\title{
ANALISIS EKONOMI ON GRID PLTS UNTUK RUMAH 2200 VA
}

\author{
Brahmantya Aji Pramudita ${ }^{1}$, Bandiyah Sri Aprillia ${ }^{2}$, Mohamad Ramdhani ${ }^{3}$ \\ Telkom University ${ }^{1,2,3}$ \\ brahmantyaajip@telkomuniversity.ac.id,bandiyah@telkomuniversity.ac.id, \\ mohamadramdhani@telkomuniversity.ac.id
}

\begin{abstract}
Electricity is a fundamental need for the Indonesian people. The increasing population in Indonesia causes increasing electricity needs. Thus, the production of electrical energy needs to be increased to fulfill the electricity needs in Indonesia. However, it cannot be fulfilled by the state's power plants. Therefore, the Indonesian government encourages renewable energy to maintain energy endurance and independence. Converting solar energy into electrical energy through photovoltaic (PV) is an alternative example to get renewable energy. The objective of this study is to analysis the economic factor of a solar energy power plant (PLTS) on-grid system on residential load type 2200VA with a different two load profile. The result of energy economics calculations for PLTS on-grid system based on Net Present Cost (NPC) and Break-Even Point (BEP) by comparing the result of houses before and after using the PLTS on-grid system. Based on the result of the experiment house is obtained a declining power by $21.89 \%$ than the compared house. Thus, NPC can decrease by 13.12\%-15.31\% with the range of electricity bills by $R p 23,060,260.00-R p$ 25,195,970.00. Meanwhile, the analysis results by looking at the capital return or BEP shows that the PLTS on-grid system of the experiment house is excellent than the compared house with BEP's Simple Payback by 7.60 years and BEP's Discounted Payback by 8.73 years.
\end{abstract}

Keywords : PLTS on-grid, residential load, Net Present Cost, Break Even Point

\begin{abstract}
Intisari - Kebutuhan listrik adalah kebutuhan dasar masyarakat Indonesia. Peningkatan jumlah penduduk di Indonesia mengakibatkan kebutuhan listrik semakin meningkat. Sehingga, produksi energi listrik perlu ditingkatkan untuk memenuhi kebutuhan listrik di Indonesia. Namun, kebutuhan listrik tidak dapat dipenuhi oleh pembangkit listrik yang dimiliki oleh negara. Oleh karena itu, energi terbarukan didorong oleh pemerintah untuk menjaga ketahanan dan kemandirian energi. Mengkonversi energi surya menjadi energi listrik melalui perangkat panel surya adalah salah satu contoh alternatif untuk mendapatkan energi terbarukan. Pada penelitian ini, bertujuan untuk menganalisis terkait faktor keekonomian sistem on grid pembangkit listrik tenaga surya pada beban rumah tangga tipe 2200VA dengan dua jenis profil beban yang berbeda. Hasil perhitungan faktor keekonomian energi untuk sistem on grid pembangkit listrik tenaga surya berdasarkan atas perhitungan Net Present Cost (NPC) dan Break Even Point (BEP) dengan cara membandingkan hasil dari rumah sebelum dan sesudah menggunakan sistem on grid PLTS. Berdasarkan hasil analisis pada rumah teliti diperoleh penurunan daya sebesar $21,89 \%$ dibandingkan dengan rumah banding. Sehingga, NPC dapat turun sebesar 13,12\%-15,31\% dengan rentang tagihan listrik sebesar Rp 23.060.260,00 - Rp 25.195.970,00. Sedangkan, hasil analisis dengan melihat kecepatan modal kembali atau BEP menunjukkan bahwa sistem on grid PLTS pada rumah teliti lebih unggul dibandingkan dengan rumah banding dengan hasil pada jenis BEP Simple Payback sebesar 7,60 tahun dan Discounted Payback sebesar 8,73 tahun.
\end{abstract}

Kata kunci : on grid PLTS, residential load, Net Present Cost, Break Even Point

\section{PENDAHULUAN}

Indonesia merupakan negara kepulauan. Jumlah pulau di Indonesia mencapai 17.504 dengan total penduduk 267 juta dan terus meningkat setiap tahunnya. Menurut Badan Pusat Statistik (BPS), meningkatan jumlah penduduk berbanding lurus dengan kebutuhan listrik. Berdasarkan pengamatan BPS, rasio elektrifikasi di Indonesia pada tahun 2020 telah mencapai $99.48 \%$. Jumlah pelanggan naik sebesar $1.18 \%$ dibandingkan tahun 2018. Jumlah pelanggan terbesar berasal dari kelompok rumah tangga dengan jumlah 62.543.434 pelanggan atau 91,88 \% [1], [2]. Lebih jauhnya, menurut Kementrian Energi dan Sumber Daya Mineral (ESDM) kapasitas pembangkit tenaga listrik yang dimiliki negara yakni Perusahaan Listrik Negara (PLN) telah mensuplai kebutuhan pengguna listrik di Indonesia dengan $67 \%$ berasal dari sumber energi tidak terbarukan dan $6,2 \%$ sumber energi terbarukan [3].

Berkurangnya potensi sumber energi fosil terutama minyak dan gas bumi, mendorong pemerintah untuk menjadikan energi baru terbarukan sebagai prioritas utama untuk menjaga ketahanan dan kemandirian energi [3]. Salah satu peraturan yang mengatur pengembangan energi baru terbarukan ialah PP No. 79 tahun 2014 tentang kebijakan energi nasional. ESDM telah memberlakukan beberapa kebijakan utama guna mempercepat pengembangan energi baru terbarukan. Salah satu kebijakan tersebut ialah sistem Feed in Tariff (FiT) [4]. Sistem FiT merupakan mekanisme kebijakan penerapan harga beli listrik dari pembangkit energi baru terbarukan oleh PLN [4]. Besarnya tarif berbeda-beda pada masingmasing jenis energi. ESDM juga mengeluarkan kebijakan terkait peningkatan porsi biofuel, peningkatan rasio elektrifikasi wilayah off-grid dalam guna meningkatkan pemanfaatan energi baru terbarukan.

Berdasarkan letak geografis kota Bandung merupakan daerah yang berpotensi untuk integrasi pembangkit listrik tenaga surya. Radiasi global minimum kota Bandung mencapai $4.57 \mathrm{kWH} / \mathrm{m}^{2}$ pada bulan januari sedangkan radiasi global maksimum mencapai $5.43 \mathrm{kWH} / \mathrm{m}^{2}$ pada bulan September [5]. Oleh karena itu, konversi energi surya menjadi energi listrik melalui perangkat panel surya dapat diimplementasikan. Integrasi pembangkit listrik tenaga surya (PLTS) dapat dikonfigurasikan secara on grid ataupun off grid [6]-[9]. Pada sistem pembangkit off grid, energi listrik dari panel surya disimpan ke dalam baterai yang terhubung ke charger controller dan inverter. Jenis inverter yang biasa digunakan pada sistem ini merupakan bidirectional inverter [10]. Inverter ini mampu mengisi energi baterai dari PLTS dan mengambil energi dari baterai untuk terhubung ke beban listrik. Sedangkan pada sistem on grid PLTS, panel surya terhubung dengan inverter on 


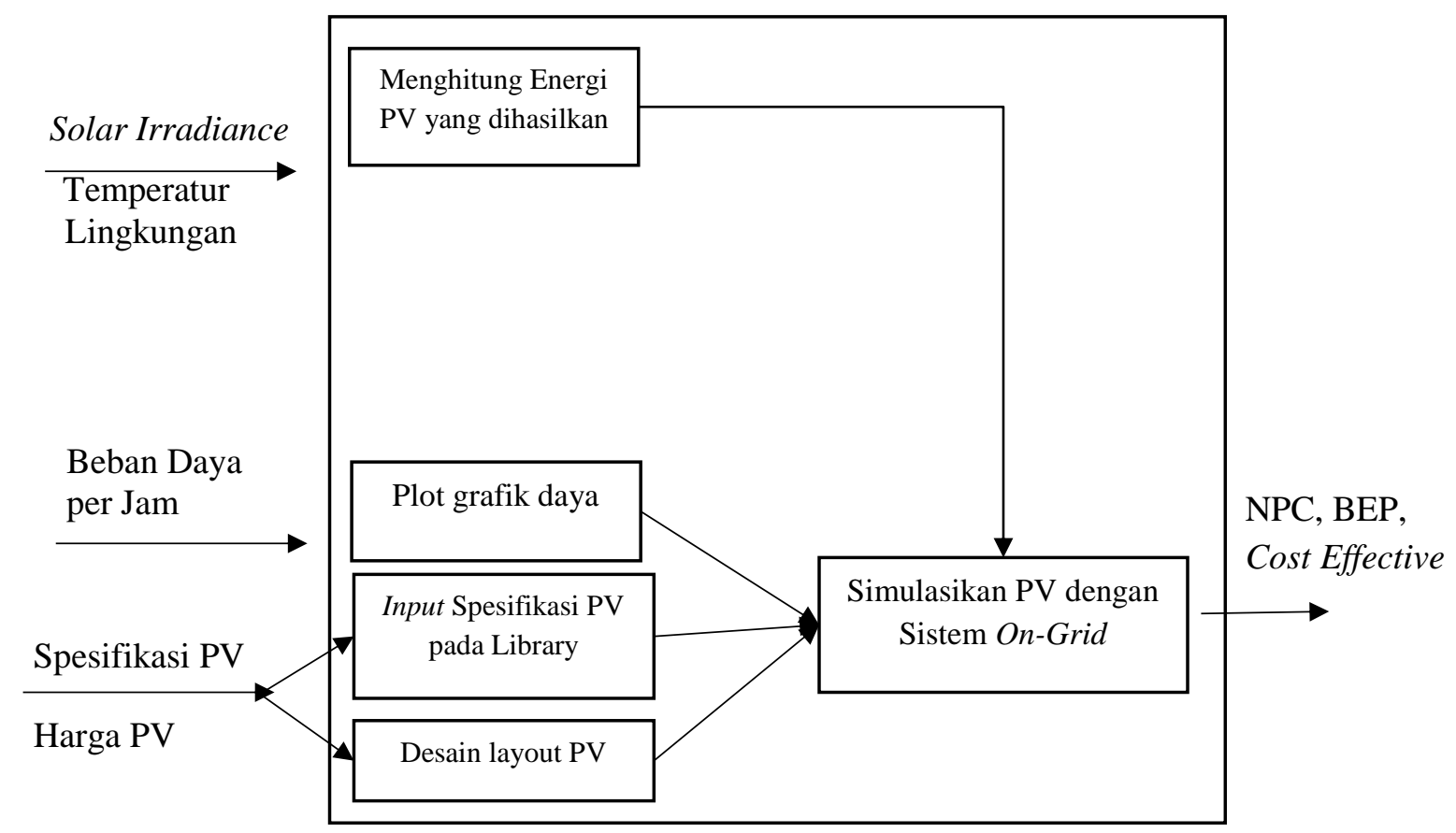

Gambar 1. Tahapan penelitian

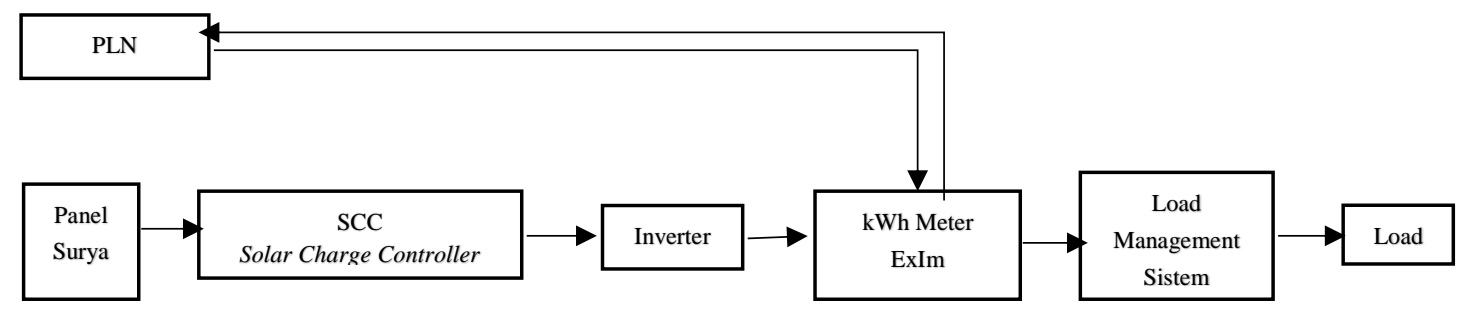

Gambar 2. Desain on grid PLTS untuk rumah 2200 VA

grid dan jaringan Pembangkit Listrik Negara (PLN). Pada sistem ini energi listrik dapat langsung dialirkan ke beban listrik.

Penelitian ini akan menyajikan studi kasus integrasi sistem on grid tenaga surya untuk beban rumah tangga 2200 VA dengan tipe profil beban yg berbeda dengan mempertimbangkan penerapan kebijakan yang telah dikeluarkan oleh Kementerian ESDM Republik Indonesia. Pada penelitian ini dilakukan percobaan dengan membandingkan hasil dari rumah teliti dengan rumah banding. Rumah teliti merupakan obyek penelitian yang digunakan untuk mengetahui Net Present Cost (NPC) dan Break Even Point (BEP) yang paling tepat untuk sistem on grid rumah 2200VA. Sedangkan, rumah banding merupakan obyek pembanding dari penelitian ini untuk membandingkan hasil analisis sebelum dan sesudah dari rumah teliti [11]. Analisis terkait faktor keekonomian energi untuk sistem on grid PLTS akan diteliti dan dievaluasi pada penelitian ini.

\section{METODE PENELITIAN}

\section{A. Metode dan Formula}

Pada Gambar 1 menjelaskan tentang tahapan penelitian yang akan dilakukan penulis. Dimulai dari mengumpulkan data dan menganalisis intensitas radiasi matahari pada lokasi rumah yang akan di tinjau pada penelitian ini. Sebelum simulasi dan analisis, peneliti harus menganalisa kebutuhan listrik untuk rumah 2200 VA. Setelah analisa kebutuhan listrik, dilanjutkan dengan perancangan desain sistem on grid PV yang optimum. Sehingga diperoleh besaran fisis terkait keekonomian energi.

\section{B. Sistem Desain}

Secara garis besar desain sistem berisikan data beban energi listrik per hari (kWh), lokasi berupa map, dan biaya komponen yang dipakai serta spesifikasinya.

Pada Gambar 2 menunjukan desain sistem instalasi energi listrik yang telah dibuat menggunakan komponen panel surya, baterai, dan inverter yang ditujukan untuk menyediakan energi pada rumah 2200 VA. Data beban dimasukan pada satu hari, data spesifikasi dari inverter yang dibutuhkan, data baterai dimasukan sesuai dengan spesifikasi yang dibutuhkan, dan data panel surya merupakan data yang telah dibuat pada aplikasi online HelioScope. Panel surya berfungsi sebagai masukan DC yang tersambung ke baterai dan tegangan pada baterai diubah menjadi tegangan $\mathrm{AC}$ oleh inverter diteruskan pada beban listrik.

\section{Profil Beban Rumah 2200VA}

Studi beban listrik merupakan metode yang digunakan untuk menghitung konsumsi energi dalam satu hari. Konsumsi energi listrik didapatkan dengan cara pembuatan daftar beban listrik (kelompok beban, jenis beban, rating daya beban) dan Pembuatan profil beban seperti pada 


\section{Daily Profile}

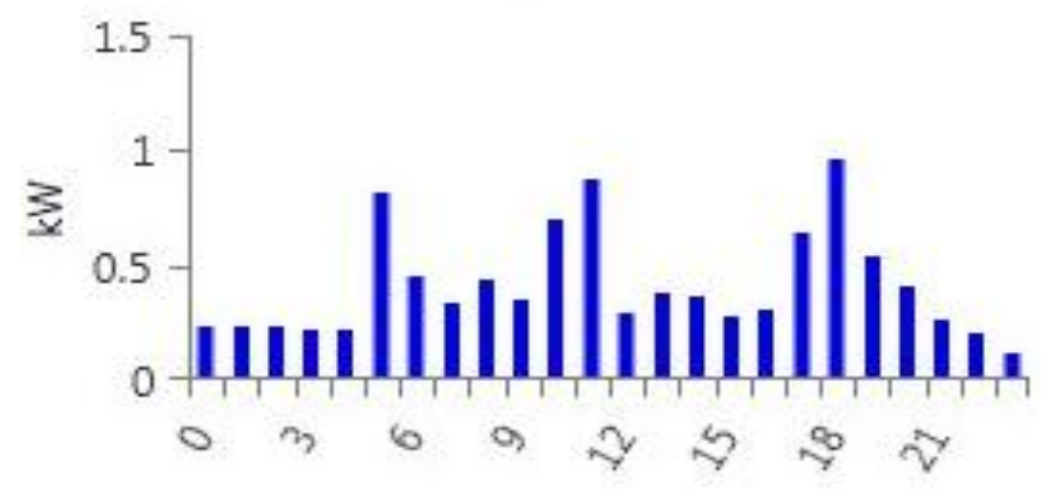

Gambar 3. Profil beban rumah 2200 VA dalam satu hari

\section{Seasonal Profile}

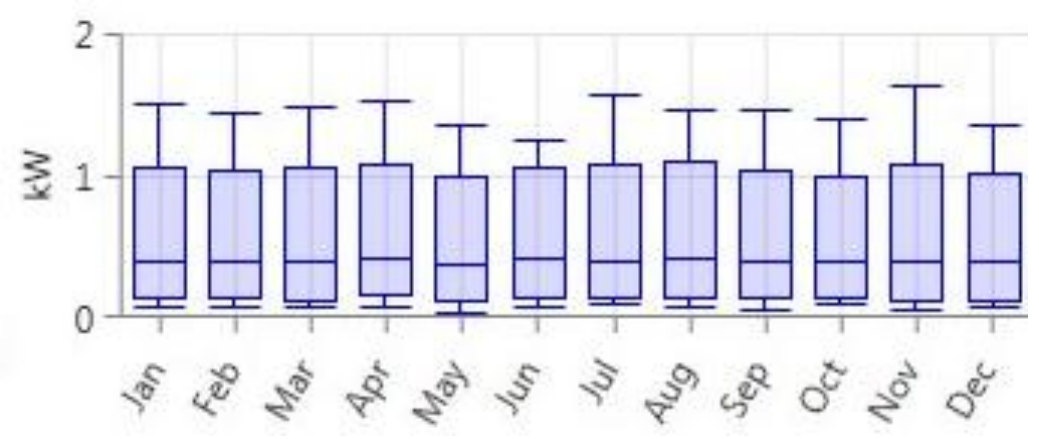

Gambar 4. Profil beban rumah 2200 VA dalam satu tahun

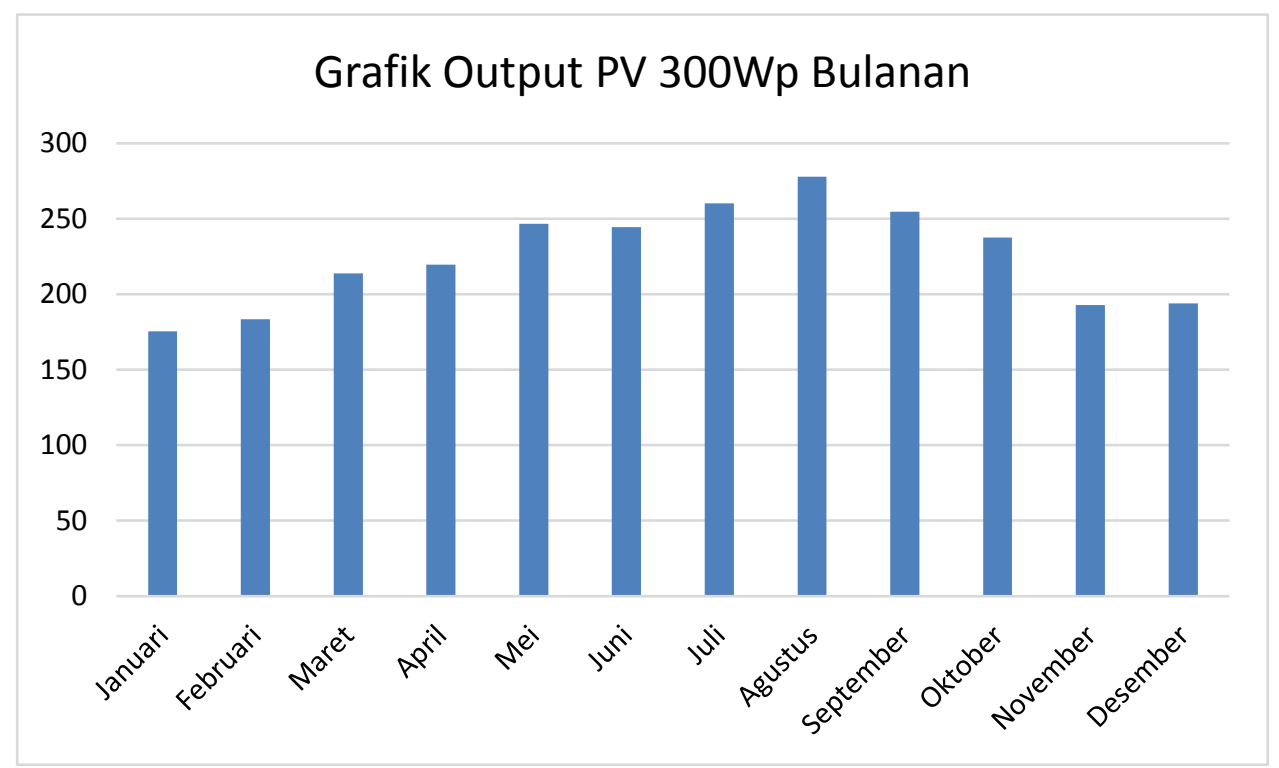

Gambar 5. Keluaran daya PV panel $300 \mathrm{Wp}$

Gambar 3 yang berisikan: waktu beban digunakan dan periode beban digunakan per hari. Sedangkan variasi profil beban disajikan pada Gambar 4.

\section{Spesifikasi Sistem}

Pada Tabel 1 menunjukan spesifikasi sistem PV yang dipakai pada penilitian ini. Komponen yang digunakan adalah inverter, PV, dan KWH EXIM.

\section{ANALISIS DAN PEMBAHASAN}

Daya yang dihasilkan oleh PV 300Wp ditunjukan pada Gambar 5. Daya yang dihasilkan sepanjang tahun yaitu

Tabel 1. Spesifikasi sistem

\begin{tabular}{|c|c|c|}
\hline Komponen & Spesifikasi & Harga komponen \\
\hline Inverter & $2 \mathrm{~kW}$ & Rp. 3.300.000 \\
\hline PV & $300 \mathrm{Wp}$ & Rp. 3.300.000 \\
\hline KWH EXIM & - & Rp. 1.600 .000 \\
\hline
\end{tabular}




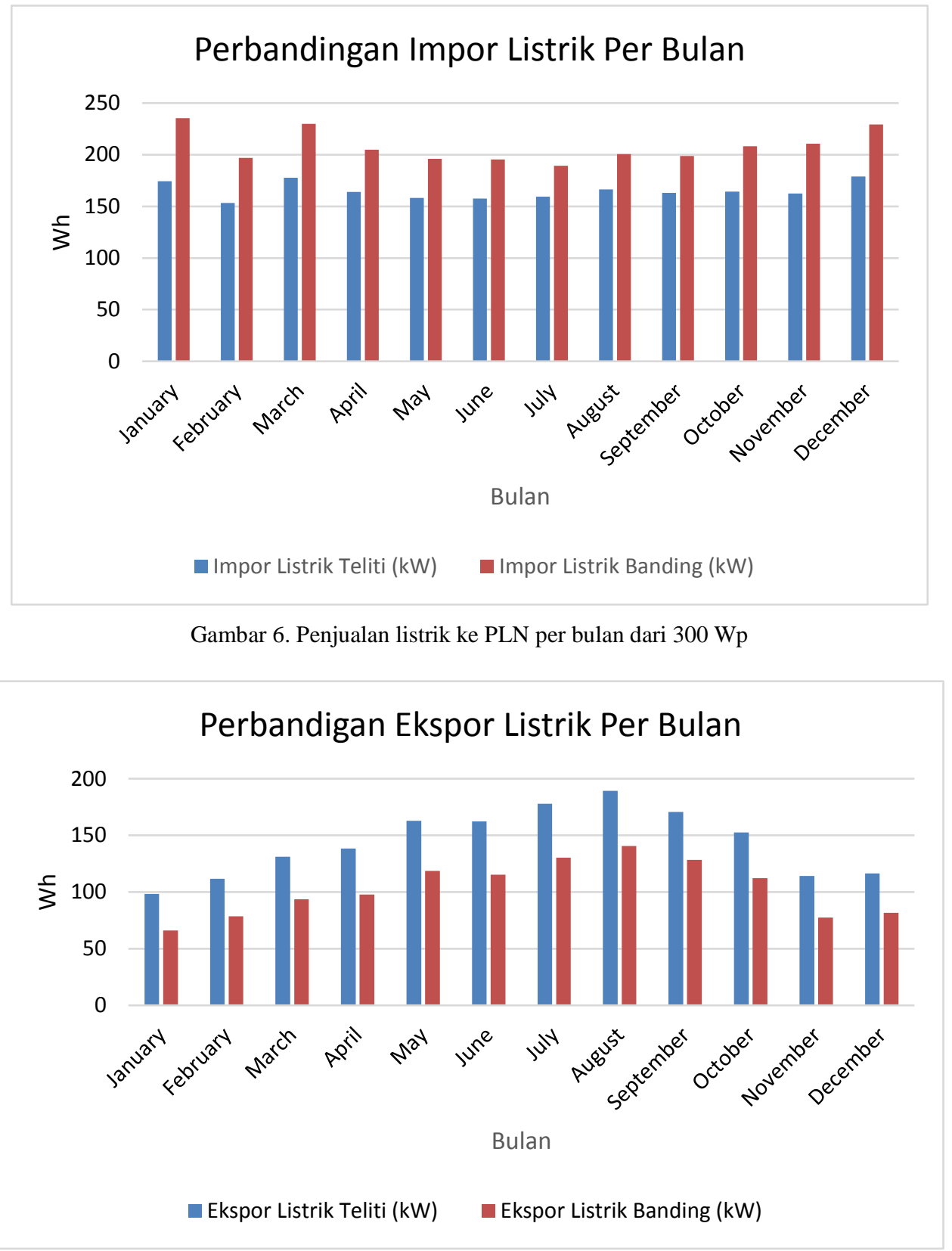

Gambar 7. Grafik ekspor listrik ke PLN dalam setahun

sebesar 2700.915619 kW. Gambar menunjukkan daya tebesar ada di bulan Maret yaitu sebesar $246.7276213 \mathrm{~kW}$. Panel surya menghasilkan daya paling rendah di bulan desember sampai pertengahan februari karena sedang musim hujan yang membuat intensitas penyinaran matahari rendah.

Pembelian listrik terjadi saat panel surya tidak menghasilkan daya atau kurang dari daya yang diperlukan saat terjadi penggunaan alat elektronik. Pembelian listrik atau dikenal impor listrik ke PLN memuncak saat dini hari sampai $1,641007 \mathrm{~kW}$ dan malam hari karena tidak adanya cahaya matahari yang mengakibatkan tidak adanya suplai dari panel surya seperti pada Gambar 6. Terlihat impor listrik yang paling banyak ada di bulan Januari yaitu sebesar 236,2529563 kW karena beban rumah sedang memuncak dan sedang musim hujan.

Penjualan listrik atau ekspor listrik ke PLN paling banyak terjadi ketika siang hari karena radiasi matahari sedang berada di puncaknya dan panel surya menghasilkan intensitas energi yang tinggi. Ekspor listrik sepanjang tahun ditunjukkan oleh Gambar 7.

Selama setahun ekspor listrik ke PLN mencapai jumlah 1241,234089 kW pertahunnya dan ekspor memuncak pada bulan Agustus dikarenakan sedang musim kemarau dan intensitas matahari lebih terik daripada biasanya, juga penggunaan daya berkurang dari biasanya seperti yang ditunjukkan pada Gambar 7.

Net Present Cost (NPC) merupakan salah satu faktor penentu para investor untuk berinvestasi, semakin kecil NPC maka semakin bagus untuk berinvestasi. NPC diperoleh dengan melihat dari nilai waktu sekarang (Present Worth). Berikut analisis hasil perhitungan jumlah tagihan listrik sebelum dan setelah pemasangan panel surya pada rumah 2200 VA disajikan pada Tabel 2.

Hasil perhitungan menunjukan bahwa dengan penurunan daya 21,89 persen, yaitu sebesar $2,15 \mathrm{kWh}$ dapat 
menurunkan NPC sebesar 13,12\% - 15,31\% yaitu dalam rentang sebesar Rp.23.060.260 - Rp.25.195.970 seperti pada Gambar 8.

Tabel 2. Hasil perbandingan perhitungan NPC

\begin{tabular}{ccc}
\hline & PLN & On-Grid 300Wp \\
\hline $\begin{array}{c}\text { Rumah Banding } \\
\text { (Rp) }\end{array}$ & 92.200 .000 & 62.141 .150 \\
\hline Rumah Teliti (Rp) & 72.000 .000 & 39.080 .890 \\
\hline
\end{tabular}

Break Even Point merupakan salah satu metode dalam analisis investasi untuk melihat secepat apa modal yang dipakai akan kembali. BEP sistem on grid PLTS dapat dihitung dengan hasil sebagai berikut. Sistem grid (PLN) nol karena jika hanya memakai suplai dari PLN maka tidak akan ada cost-saving dan ini merupakan base case system sebagai pembanding sistem lainnya. Jika menginginkan modal kembali dengan cepat maka dapat memilih pemasangan sistem on grid dengan kapasitas panel surya $300 \mathrm{Wp}$.

\section{KESIMPULAN}

Penggunaan pembangkit listrik tenaga surya sistem on grid merupakan salah satu cara untuk memenuhi kebutuhan lisrik untuk beban rumah tangga. Pada penelitian ini, bertujuan untuk menganalisis terkait faktor keekonomian sistem on grid pembangkit listrik tenaga surya pada beban rumah tangga tipe 2200VA dengan dua jenis profil beban yang berbeda. Berdasarkan hasil analisis pada rumah teliti diperoleh penurunan daya sebesar $21,89 \%$ dibandingkan dengan rumah banding. Sehingga, NPC dapat turun sebesar $13,12 \%-15,31 \%$ dengan rentang tagihan listrik sebesar Rp 23.060.260,00 - Rp 25.195.970,00. Sedangkan, hasil analisis dengan melihat kecepatan modal kembali atau BEP menunjukkan bahwa sistem on grid PLTS pada rumah teliti lebih unggul dibandingkan dengan rumah banding dengan hasil pada jenis BEP Simple Payback sebesar 7,60 tahun dan Discounted Payback sebesar 8,73 tahun.

\section{DAFTAR PUSTAKA}

[1] A. Triboesono, Statistik Ketenagalistrikan 2017 Edisi No. 31 Tahun Anggaran 2018. Jakarta Selatan: Direktorat Jenderal Ketenagalistrikan Kementrian Energi dan Sumber Daya Mineral, 2018.

[2] A. Sugiyono, P. Teknologi, S. Energi, I. Kimia, B. Pengkajian, and P. Teknologi, "OUTLOOK ENERGI INDONESIA 2015-2035: PROSPEK ENERGI BARU TERBARUKAN Indonesia Energy Outlook 2015-2035: New and Renewable Energy Prospect."

[3] A. C. Adi et al., Handbook of Energy and Economic Statistics of Indonesia 2018. Ministry of Energy and Mineral Resources Republic of Indonesia, 2019.

[4] D. Yuliani, "Is feed-in-tariff policy effective for increasing deployment of renewable energy in Indonesia?," in The Political Economy of Clean Energy Transitions, 2016, p. 144.

[5] R. Darussalam, A. Rajani, ... K. K.-.. N. F. (E, and undefined 2016, "PENGATURAN ARAH AZIMUTH DAN SUDUT TILT PANEL PHOTOVOLTAIC UNTUK OPTIMALISASI RADIASI MATAHARI, STUDI KASUS: BANDUNG â€"JAWA,” journal.unj.ac.id.
[6] B. S. Aprillia and M. A. Foury Rigoursyah, "Design OnGrid Solar Power System for 450 VA Conventional Housing using HOMER Software," IOP Conf. Ser. Mater. Sci. Eng., vol. 771, no. 1, 2020, doi: 10.1088/1757899X/771/1/012011.

[7] A. Al Nabulsi, "Efficiency optimization of a DSP-based standalone PV system using fuzzy logic and dual-MPPT control," IEEE Trans. Ind. informatics, vol. 8, no. 3, pp. 573-583, 2012.

[8] L. Xu, Y. Wang, Y. Solangi, H. Zameer, and S. Shah, "OffGrid Solar PV Power Generation System in Sindh, Pakistan: A Techno-Economic Feasibility Analysis," Processes, vol. 7, no. 5, p. 308, May 2019, doi: 10.3390/pr7050308.

[9] V. Salas, W. Suponthana, and R. A. Salas, "Overview of the off-grid photovoltaic diesel batteries systems with AC loads," Applied Energy, vol. 157. Elsevier Ltd, pp. 195-216, 01-Nov-2015, doi: 10.1016/j.apenergy.2015.07.073.

[10] M. Naim, "Rancangan Sistem Kelistrikan PLTS Off Grid 1000 Watt Di Desa Mahalona Kecamatan Towuti," Din. J. Ilm. Tek., 2017.

[11] Y. Nurfaidah, I. P. D. Wibawa, B. N. D. Aprilia, C. Ekaputri, and M. Reza, "Analysis of smart house power savings with on-grid photovoltaic power system," J. Phys. Conf. Ser., vol. 1367, no. 1, 2019, doi: 10.1088/1742 $6596 / 1367 / 1 / 012047$. 